\title{
KONFIGURASI DAN MANAJEMEN WINDOWS SERVER 2008 DI SMK NEGERI 1 SETIA JANJI
}

\author{
Guntur Maha Putra ${ }^{1}$, Afdhal Syafnur ${ }^{2}$, Rolly Yesputra ${ }^{3}$ \\ ${ }^{1,2}$ Program Studi Sistem Informasi, STMIK Royal Kisaran, \\ ${ }^{3}$ Program Studi Sistem Komputer, STMIK Royal Kisaran, \\ email :'igoenputra@gmail.com
}

\begin{abstract}
This community service activity is held in SMK Negeri 1 Setia Janji on the students of RPL (Software Engineering), amounting to 23 people. The purpose of the implementation of this activity is to provide training to participants about windows server 2008 management and implementation and configuration that has not been previously taught, so it is expected to improve the new skills for each participant. The method of implementing community service is done by providing training with the stages of the delivery of the material from the module and direct practice in the laboratory room. From the results of observations, interviews undertaken and the findings can be concluded that this community service activity provides a very large and targeted benefits, thereby providing additional insight and new knowledge in the field of information technology, especially windows server 2008 outside of learning that had been received by students in SMK Negeri 1 Setia Janji.
\end{abstract}

Keywords: windows server 2008, configuration, management

\begin{abstract}
Abstrak : Kegiatan pengabdian kepada masyarakat ini dilaksanakan di SMK Negeri 1 Setia Janji pada siswa-i jurusan RPL (Rekayasa Perangkat Lunak) yang berjumlah 23 orang. Tujuan dari pelaksanaan kegiatan ini adalah untuk memberikan pelatihan kepada peserta mengenai manajemen windows server 2008 beserta implementasi maupun konfigurasinya yang sebelumnya belum pernah diajarkan, sehingga diharapkan dapat meningkatkan keterampilan baru bagi diri masing-masing peserta. Metode pelaksanaan pengabdian kepada masyarakat dilakukan dengan cara memberikan pelatihan dengan tahapan penyampaian materi dari modul yang diberikan dan praktek langsung di ruang laboratorium. Dari hasil pengamatan, wawancara yang di lakukan serta temuan yang kami dapatkan dapat disimpulkan bahwa program pengabdian masyarakat ini memberikan manfaat yang sangat besar dan tepat sasaran, sehingga memberikan tambahan wawasan serta pengetahuan baru di bidang teknologi informasi, khususnya windows server 2008 di luar pembelajaran yang selama ini di terima oleh siswa-i di SMK Negeri 1 Setia Janji.
\end{abstract}

Kata kunci : windows server 2008, konfigurasi, manajemen

\section{PENDAHULUAN}

Teknologi informasi dan telekomunikasi pada saat ini sangat berkembang pesat dan telah terbukti sebagai sarana komunikasi dan sumber informasi yang sangat handal. Seiring dengan kemajuan dan perkembangan teknologi yang semakin canggih dan cepat juga dapat dilihat implementasinya 
Vol. 1, No. 2, Jul 2018, hlm. $41-44$

ISSN 2614-7912 (cetak)

ISSN 2622-3813 (online)

Available online at http://jurnal.stmikroyal.ac.id/index.php/jurdimas

pada bidang jaringan komputer khususnya tentang client server misalnya saja penggunaan dari window server 2008.

Kelancaran administrasi suatu perusahaan / instansi secara optimal dan maksimal dapat dilakukan dengan membangun privileges berbasis active directory pada jaringan komputer yang telah ada dengan perangkat lunak sistem operasi windows server 2008 enterprise yang nantinya akan diinstal pada komputer server. Dengan adanya privileges berbasis active directory dapat memudahkan pekerjaan administrator dalam melakukan manajemen user dan group, pemberian hak akses (privileges) setiap user dan group, tidak harus melakukan setting satu per satu pada komputer client. Menyahuti kebutuhan perusahaan / instansi akan manajemen administrasi organisasinya menggunakan windows server 2008, maka perlu dipersiapkan pembangunan Sumber Daya Manusia (SDM) yang mumpuni menguasai konfigurasi dan manajemen windows server 2008 dalam bentuk pelatihan yang tercakup pada program kegiatan pengabdian masyarakat oleh tim dosen yang tergabung didalamnya.

Rumusan masalah dari pengabdian kepada masyarakat ini adalah sebagai berikut :

a. Bagaimana siswa/i dapat memahami sistem berbasis server khususnya windows server 2008.

b. Bagaimana mengkonfigurasi dan memanajemen sistem operasi windows server 2008.

Tujuan dari kegiatan ini adalah memberikan pelatihan kepada peserta mengenai perencanaan manajemen administrasi windows server 2008 beserta implementasi maupun konfigurasinya, sehingga diharapkan dapat meningkatkan keterampilan diri masing-masing peserta.

Manfaat dari pelaksanaan kegiatan pengabdian kepada masyarakat ini adalah :

a. Peserta dapat memahami konfigurasi dan manajemen windows server 2008. b. Dapat menjadi landasan atau dasar pemikiran siswa/i untuk mengembangkan konfigurasi dan manajemen server dengan sistem operasi yang berbeda misalnya linux.

c. Sebagai wadah penyaluran ilmu dan amal bagi dosen STMIK Royal Kisaran dalam ranah pengabdian masyarakat.

\section{METODE}

Metode pelaksanaan pengabdian kepada masyarakat ini adalah dengan cara melaksanakan kegiatan pelatihan dalam bentuk penyampaian materi dari modul yang diberikan dan praktek langsung kepada 23 orang siswa/i. Berikut beberapa foto-foto dokumentasinya :

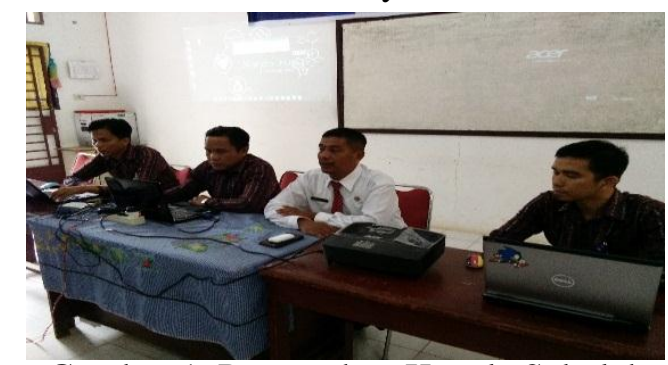

Gambar 1. Pengarahan Kepala Sekolah Sekaligus Pembukaan Kegiatan Pengabdian

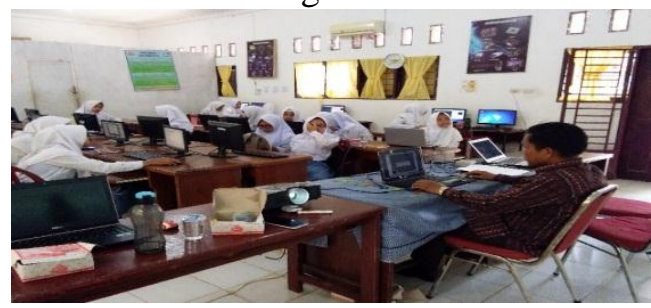

Gambar 2. Praktek Instalasi Windows Server 2008

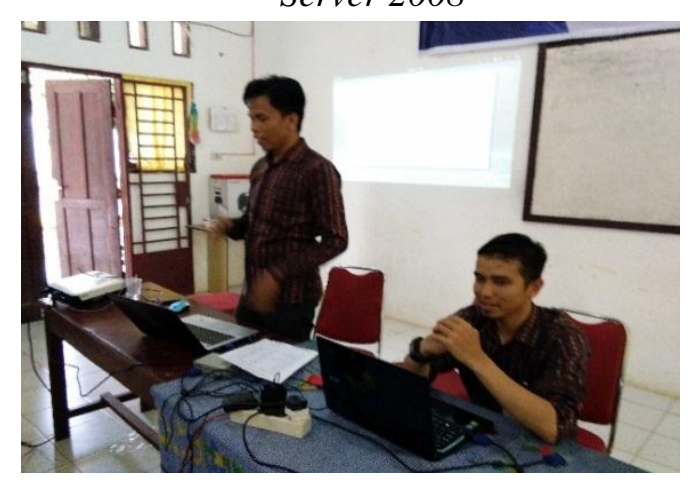


Vol. 1, No. 2, Jul 2018, hlm. $41-44$

Available online at http://jurnal.stmikroyal.ac.id/index.php/jurdimas

Gambar 3. Praktek Manajemen dan

Konfigurasi Windows Server 2008

Pemberian modul diharapkan agar memberikan kemudahan bagi para siswa/i untuk mempelajari ulang materi yang diajarkan setelah kegiatan selesai dilaksanakan

\section{PEMBAHASAN}

Windows Server 2008 adalah nama sistem operasi untuk server dari perusahaan Microsoft. Sistem server ini merupakan pengembangan dari versi sebelumnya yang disebut Windows Server 2003. Pada tanggal 15 Mei 2007, Bill Gates mengatakan pada konferensi WinHEC bahwa Windows Server 2008 adalah nama baru dari Windows Server "Longhorn".

Windows Server 2008 dibangun dari kode yang sama seperti Windows Vista, karenanya Windows Server 2008 memiliki arsitektur dan fungsionalitas yang sama dengannya. Karena Windows Vista, oleh Microsoft, menawarkan kemajuan secara teknis dibandingkan dengan Windows versi sebelumnya, maka hal-hal yang dimiliki oleh Windows Vista juga dimiliki oleh Windows Server 2008. Contohnya adalah network stack yang ditulis lagi dari awal (IPv6, jaringan nirkabel, kecepatan, dan peningkatan keamanan); instalasi yang lebih mudah; diagnosa, pemantauan dan pencatatan yang lebih baik; keamanan yang lebih tangguh seperti BitLocker Drive Encryption, Address Space Layout Randomization (ASLR), Windows Firewall yang lebih baik; teknologi Microsoft .NET Framework 3.0, seperti Windows Communication Foundation, Microsoft Message Queuing (MSMQ), dan Windows Workflow Foundation (WFW), dan juga peningkatan pada sisi kernel.

Peserta dari kegiatan pengabdian kepada masyarakat yang berbentuk pelatihan, adalah siswa/i dari SMK Negeri
1 Setia Janji dengan jurusan Rekayasa Perangkat Lunak (RPL) yang berjumlah 23 orang. Ketuntasan hasil kegiatan dapat dilihat dengan pengamatan maupun penilaian dari teori / praktikum yang dikerjakan. Keberhasilan dari kegiatan yang dilakukan diukur dengan rata-rata persentase keseluruhan materi / praktek yang dilakukan siswa dengan target capaian $>=70 \%$. Untuk menghitung persentase ketuntasan siswa dalam kegiatan pengabdian ini, digunakan rumus berikut:

Persentase ketuntasan $=\frac{\text { Jumlah siswa tuntas }}{\text { jumlah siswa }} \times 100 \%$

Dalam kegiatan pengabdian yang dilakukan dibahas mengenai materimateri yang dipraktekkan secara langsung yang dapat dilihat persentase ketuntasannya dari tabel berikut:

Tabel 1. Persentase Materi dan Praktek

\begin{tabular}{|l|c|c|}
\hline \multicolumn{1}{|c|}{$\begin{array}{c}\text { Bahasan Materi \& } \\
\text { Praktek }\end{array}$} & $\begin{array}{c}\text { Tuntas } \\
\text { (orang) }\end{array}$ & $\begin{array}{c}\text { Perse } \\
\text { ntase } \\
(\%)\end{array}$ \\
\hline $\begin{array}{l}\text { a. Instalasi Windows } \\
\text { Server 2008 dan } \\
\text { Client }\end{array}$ & 23 & $\begin{array}{c}100 \\
\%\end{array}$ \\
\hline $\begin{array}{l}\text { b. Install Active } \\
\text { Directory }\end{array}$ & 22 & $96 \%$ \\
\hline $\begin{array}{l}\text { c. Koneksi Domain } \\
\text { Pada Komputer } \\
\text { Client }\end{array}$ & 20 & $87 \%$ \\
\hline $\begin{array}{l}\text { d. Manajemen } \\
\text { Organization Unit, } \\
\text { Group Dan User }\end{array}$ & 18 & $78 \%$ \\
\hline $\begin{array}{l}\text { e. Sharing File Dan } \\
\text { Security }\end{array}$ & 18 & $74 \%$ \\
\hline $\begin{array}{l}\text { f. Web Server (IIS) } \\
\text { Dan File Transfer } \\
\text { Protocol (FTP) }\end{array}$ & 17 & $86 \%$ \\
\hline $\begin{array}{l}\text { Rata-rata persentase } \\
\text { keseluruhan }\end{array}$ & \\
\hline
\end{tabular}


Vol. 1, No. 2, Jul 2018, hlm. 41 - 44

Available online at http://jurnal.stmikroyal.ac.id/index.php/jurdimas

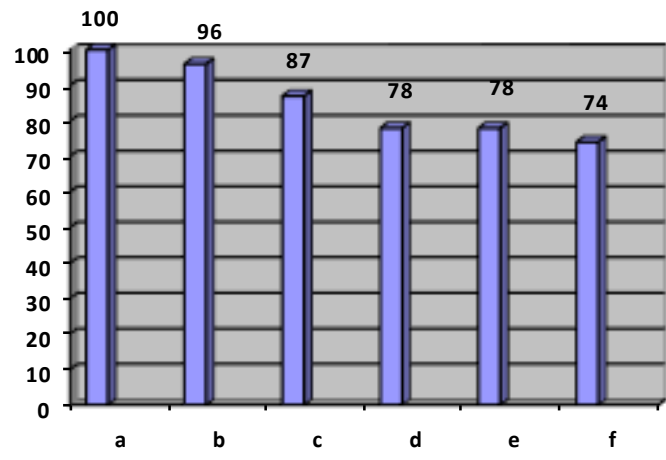

Gambar 4. Grafik Persentase Materi dan Praktek

\section{SIMPULAN}

Kesimpulan dari kegiatan pengabdian kepada masyarakat ini adalah sebagai berikut :

1. Dari hasil pengamatan, wawancara yang di lakukan serta temuan yang kami dapatkan, dapat disimpulkan bahwa program pengabdian masyarakat ini memberikan manfaat yang baik dan tepat sasaran, sehingga memberikan tambahan wawasan serta pengetahuan baru di bidang teknologi informasi khususnya windows server 2008 diluar pembelajaran yang selama ini di terima oleh siswa-i di SMK Negeri 1 Setia Janji

2. Dari 23 orang siswa/i yang mengikuti kegiatan pengabdian, jika dirataratakan persentase ketuntasan mencapai rata-rata $86 \%$. Hal ini berarti secara rata-rata kegiatan pengabdian kepada masyarakat telah berhasil dilakukan dengan baik karena telah melampaui dari target capaian yaitu $>=70 \%$.

3. Dengan adanya privileges berbasis active directory, memudahkan pekerjaan administrator dalam memanajemen organization unit, group dan user, pemberian hak akses (privileges) setiap user dan group, tidak harus melakukan setting satu per satu pada komputer client.

4. Respon kepala sekolah dan siswa-siswi sangat antusias, yang tercermin dengan adanya komunikasi timbal balik dengan para siswa sampai dengan akhir kegiatan pengabdian.

\section{UCAPAN TERIMA KASIH}

Ucapan terima kasih kami sampaikan kepada Ketua Yayasan Royal Teladan Kisaran Bapak Anda Putra Lubis, SE., M.MA yang telah mendanai kegiatan ini. Tak lupa, kami juga menyampaikan terimakasih kepada Kepala Sekolah SMK Negeri 1 Setia Janji, Bapak Drs. Miswardinaf beserta jajarannya yang telah membantu terlaksananya kegiatan pengabdian kepada masyarakat ini.

\section{DAFTAR PUSTAKA}

Madcoms. (2009). "Membangun Sistem Jaringan Komputer”, Yogyakarta, Andi Publisher.

Syafizal, M. J. (2005). "Pengantar Jaringan Komputer”, Yogyakarta, Andi Offset.

Sugeng, W \& Putri, T . D. (2015). "Jaringan Komputer Dengan TCP/IP", Bandung, Modula.

I Putu Agus Eka Pratama, (2014). "Handbook Jaringan Komputer", Bandung, Informatika Bandung. 